\title{
A EDUCAÇÃO NO BRASIL: DESENVOLVIMENTO E DESIGUALDADES
}

\author{
EDUCATION IN BRAZIL: DEVELOPMENT AND INEQUALITIES \\ EDUCACIÓN EN BRASIL: DESARROLLO Y DESIGUALDADES
}

\author{
Débora Peruchin \\ Universidade de Caxias do Sul (UCS) \\ E-mail: dperuchin@ucs.br
}

\begin{abstract}
RESUMO
Este trabalho apresenta relações entre desenvolvimento, desigualdade e educação, com foco específico no Brasil. É feita uma breve contextualização das desigualdades em âmbito global, caracterizadas por uma desigual distribuição de renda. A educação é apontada como um caminho para a igualdade. O sistema educacional brasileiro é apresentado considerando seus objetivos e os problemas a serem enfrentados. A sociedade brasileira historicamente é caracterizada pela exclusão econômica e social de grande parte da população. O sistema educacional reflete as desigualdades existentes na sociedade. Há, portanto, a necessidade de políticas públicas que priorizem o combate à pobreza e às desigualdades. Assim, existem muitos desafios a serem enfrentados no Brasil para que seja ofertada uma educação de qualidade a todos os cidadãos do país.
\end{abstract}

PALAVRAS-CHAVE: Educação. Desenvolvimento. Desigualdade.

\section{ABSTRACT}

This study presents relations between development, inequality and education, with specific focus in Brazil. It is made a brief contextualization of inequalities in the global context, characterized by an unequal distribution of income. Education is indicated as a way for the equality. The Brazilian educational system is presented considering its objectives and the problems to be faced. Historically, the Brazilian society is characterized by economic and social exclusion of a large part of the population. The educational system reflects the inequalities that exist in society. Therefore, there is a need for public policies to prioritize combating the poverty and inequalities. Then, there are many challenges to be faced in Brazil to be offered a quality education to all citizens of the country.

KEYWORDS: Education. Development. Inequality.

\section{RESUMEN}

Este estudio presenta relaciones entre desarrollo, desigualdad y educación, con un enfoque especifico en Brasil. Se hace una breve contextualización de las desigualdades en el contexto global, caracterizadas por una distribución desigual de la renta. La educación se señala como un camino hacia la igualdad. Se presenta el sistema educativo brasileño teniendo en cuenta sus objetivos y los problemas a enfrentar. Históricamente la sociedad brasileña se caracteriza por la exclusión económica y social de una gran parte de la población. El sistema educativo refleja las desigualdades que existen en la sociedad. Por tanto, es necesario que las políticas públicas den prioridad a la lucha contra la pobreza y las desigualdades. Así, hay muchos desafios a enfrentar en Brasil para ofrecer una educación de calidad a todos los ciudadanos del pais.

PALABRAS-CLAVE: Educación. Desarrollo. Desigualdad..

\section{INTRODUÇÃO}

Em nível mundial, estão ocorrendo transformações sociais, econômicas e culturais de forma rápida, ampla e profunda (SARAIVA; VEIGA-NETO, 2009). Nesse contexto, para o desenvolvimento socioeconômico é necessária a redução da pobreza no mundo com a 


\section{Revista Triângulo}

ISSN 2175-1609

prestação de serviços básicos aos pobres, como saúde, educação e segurança (LIBÂNEO, 2012).

A desigualdade historicamente depende da política, por meio dos interesses que predominam na época e considerando as escolhas dos atores políticos, sociais e econômicos.

Camponês ou nobre, operário ou dono de fábrica, servente ou banqueiro: cada um, a partir de seu ponto de vista peculiar e único, vê aspectos importantes sobre as condições de vida de uns e de outros, sobre as relações de poder e de dominação entre grupos sociais, e elabora sua própria concepção do que é justo e do que não é (PIKETTY, 2014, p. 10).

Essas visões diferentes a respeito da distribuição da riqueza geram conflitos políticos, de acordo com os interesses de cada classe. Conforme Piketty (2014), o princípio de acumulação infinita, descrito por Marx, afirmava a tendência de um acúmulo do capital com a concentração do mesmo em poder de uma parcela restrita da população.

\section{REFERENCIAL TEÓRICO}

\subsection{Desigualdade e distribuição de renda}

A competição característica do capitalismo acentua as desigualdades. Segundo Sennett, "os bem-sucedidos levam a mesa toda, enquanto a massa dos perdedores fica com migalhas para dividir entre si” (1999, p. 105). A desigualdade, assim, amplia seu alcance e aumenta a distância entre ricos e pobres (SILVA, 2015).

Os processos de acumulação e distribuição de riqueza geram grande desigualdade. Há uma grande disparidade no caso de rendas derivadas do trabalho. Por exemplo, entre o salário de um executivo de grandes empresas e o restante da população (PIKETTY, 2014). Piketty diferencia a renda em dois componentes: os rendimentos do trabalho, como salários, gratificações e bônus; e a renda do capital, que provém de aluguéis, juros, lucros e "outros rendimentos obtidos do simples fato de ser dono do capital sob a forma de terras, imóveis, ativos financeiros, equipamentos industriais, etc." (2014, p. 24). Segundo ele, são produzidas desigualdades insustentáveis quando a taxa de remuneração do capital ultrapassa a taxa de crescimento da produção.

Piketty defende que, para diminuir a desigualdade, é necessário um processo de difusão de conhecimentos:

Ao adotar os métodos de produção e alcançar os níveis de qualificação de mão de obra dos países mais ricos, as economias emergentes conseguiram promover saltos na produtividade, aumentando a renda nacional. Esse processo de convergência tecnológica pode ser favorecido pela abertura 


\section{Revista Triângulo}

ISSN 2175-1609

comercial, mas trata-se, em essência, de um processo de difusão e partilha do conhecimento - o bem público por excelência -, e não de um mecanismo de mercado (PIKETTY, 2014, p. 28).

Essa difusão do conhecimento depende das políticas de educação, com investimento na qualificação pessoal. A educação tem fundamental importância nesse processo: "No longo prazo, a força que de fato impulsiona o aumento da igualdade é a difusão do conhecimento e a disseminação da educação de qualidade" (PIKETTY, 2014, p. 29). Além de oferecer conhecimentos técnicos, a educação também deve proporcionar a formação humana, buscando promover o efetivo exercício da cidadania.

\subsection{Contexto de desigualdades no Brasil}

O Brasil é um país em que há forte concentração de renda e no qual grande parte da população está em condições de pobreza (HADDAD, 2008), sendo excluída do acesso a condições mínimas de dignidade e cidadania (BARROS; HENRIQUE; MENDONÇA, 2000). A renda constitui-se em um obstáculo para o acesso dos mais pobres a serviços básicos, acesso este que deveria ser parte integrante de uma vida decente (ARRETCHE, 2015).

A pobreza, evidentemente, não pode ser definida de forma única e universal. Contudo, podemos afirmar que se refere a situações de carência em que os indivíduos não conseguem manter um padrão mínimo de vida condizente com as referências socialmente estabelecidas em cada contexto histórico (BARROS; HENRIQUE; MENDONÇA, 2000, p. 124).

No Brasil, a pobreza é um problema relacionado à distribuição desigual dos recursos e não à sua escassez. Apesar de ser constituída por muitos pobres, a população brasileira não figura entre as mais pobres do mundo. Comparado aos países desenvolvidos, o Brasil não é considerado um país rico, enquanto na comparação com outros países em desenvolvimento, "está entre os que apresentam melhores condições de enfrentar a pobreza de sua população" (BARROS; HENRIQUES; MENDONÇA, 2000, p. 126).

Nas últimas décadas, foram reduzidas as desigualdades entre os brasileiros, apesar de o país continuar entre os mais desiguais do mundo (ARRETCHE, 2015). Segundo Haddad, foram percebidos pequenos avanços,

[...] como a redução do analfabetismo e da mortalidade infantil; o crescimento das matrículas no ensino público; a melhoria no acesso das comunidades mais pobres à infraestrutura de abastecimento de água, saneamento e energia elétrica; e a implementação de políticas de transferência de renda para os mais pobres, principalmente no Norte e Nordeste (2007, p. 203). 


\section{Revista Triângulo}

ISSN 2175-1609

Em 2014, por exemplo, segundo a Pesquisa Nacional por Amostra de Domicílios (PNAD), a desigualdade no Brasil diminuiu pelo décimo ano seguido. Embora a maior queda na desigualdade entre 2013 e 2014 tenha sido registrada no Nordeste, esta é ainda a região com maior desigualdade no Brasil (IBGE, 2015). Nas regiões mais pobres do país, faltam oportunidades de trabalho e há carência dos serviços básicos de infraestrutura, contrastando com as regiões mais ricas, como Sul e Sudeste, respectivamente as regiões com menor desigualdade e maior crescimento do PIB (ARRETCHE, 2015).

Mesmo havendo um crescimento econômico nas últimas décadas, permanece no Brasil uma intensa concentração de renda que mantém a desigualdade social como principal característica da organização social brasileira (HADDAD, 2007). Segundo Barros, Henriques e Mendonça, "os elevados níveis de pobreza que afligem a sociedade encontram seu principal determinante na estrutura da desigualdade brasileira - uma perversa desigualdade na distribuição da renda e das oportunidades de inclusão econômica e social” (2000, p. 123).

De acordo com Arretche, há relação entre a renda dos domicílios e os obstáculos para o acesso aos serviços básicos de infraestrutura:

Os domicílios mais pobres e as regiões com maior concentração de domicílios pobres apresentam sistematicamente desvantagens de acesso. $\mathrm{Na}$ verdade, estes acumulam uma superposição de desvantagens sob a forma de ausência simultânea de vários serviços $(2015$, p. 447).

O grau de desigualdade no Brasil é um dos mais elevados do mundo, o que justifica o fato de seu nível de pobreza ser mais elevado do que em países com renda per capita similar à brasileira (BARROS; HENRIQUES; MENDONÇA, 2000). O Brasil

[...] não é um país pobre, mas um país extremamente injusto e desigual, com muitos pobres. A desigualdade encontra-se na origem da pobreza e combatê-la torna-se um imperativo. Imperativo de um projeto de sociedade que deve enfrentar o desafio de combinar democracia com eficiência econômica e justiça social. Desafio clássico da era moderna, mas que toma contornos de urgência no Brasil contemporâneo (BARROS; HENRIQUES; MENDONÇA, 2000, p. 141).

É importante e necessário, nesse contexto, que as políticas públicas priorizem a redução da desigualdade e o combate à pobreza. No Brasil, as políticas recentes demonstraram que geram impacto sobre a pobreza e a desigualdade (ARRETCHE, 2015), devendo enfrentar especialmente a desigualdade de renda, historicamente presente no Brasil.

\subsection{A educação no Brasil}

Segundo a Constituição Federal Brasileira (BRASIL, 2016), a educação é um direito social (C) Rev. Triang. \begin{tabular}{l|l|l|} 
Uberaba, $\mathrm{MG}$ & $\mathrm{v} .11$ & $\mathrm{n} .2$
\end{tabular} p. $199-210$ 


\section{Revista Triângulo}

ISSN 2175-1609

fundamental, devendo ser garantida pelo Estado, pela família e pela sociedade. São considerados também como direitos sociais: a saúde, a alimentação, o trabalho, a moradia, o lazer, a segurança, a previdência social, a proteção à maternidade e à infância e a assistência aos desamparados.

Um dos deveres do Estado quanto à educação é garantir a igualdade de condições para o acesso e permanência na educação básica (CARREIRA, 2013; SAMPAIO, 2014). No mesmo sentido, o Estatuto da Criança e do Adolescente estabelece que:

É dever da família, da comunidade, da sociedade em geral e do poder público assegurar, com absoluta prioridade, a efetivação dos direitos referentes à vida, à saúde, à alimentação, à educação, ao esporte, ao lazer, à profissionalização, à cultura, à dignidade, ao respeito, à liberdade e à convivência familiar e comunitária (BRASIL, 2005, p.23).

Especificamente quanto à educação, foi promulgada a Lei de Diretrizes e Bases da Educação Nacional (LDB) - lei no 9.394/1996 - legislação esta que disciplina a educação escolar (BRASIL, 2017).

O Sistema Educacional Brasileiro está organizado em Educação Básica e Ensino Superior. A Educação Básica é formada pela Educação Infantil, Ensino Fundamental e Ensino Médio. Nela há ainda modalidades específicas, como a educação de jovens e adultos (EJA), a educação profissional, a especial para portadores de deficiência e a escolar indígena. O Ensino Superior contempla, em geral, de quatro a seis anos de estudos, além da pós-graduação (HADDAD, 2008, p. 32).

Deve-se pensar a educação a partir da relação entre seus níveis de ensino e modalidades, considerando que a educação infantil e os ensinos fundamental, médio, profissional e superior são complementares entre si (HADDAD, 2013).

O acesso aos sistemas de ensino no Brasil vem sendo ampliado, incluindo setores da sociedade que anteriormente eram totalmente excluídos. A população e os legisladores assim, gradualmente aumentam o reconhecimento da educação como um direito humano. Entretanto, as avaliações no Brasil em sistemas internacionais ainda são muito inferiores ao obtido por outros países em desenvolvimento e pelos países desenvolvidos (HADDAD, 2007), refletindo os problemas da escola pública brasileira, que há décadas são um desafio para órgãos públicos e pesquisadores das ciências humanas e sociais (LIBÂNEO, 2012).

Segundo Libâneo (2012), um dos motivos do insucesso da escola pública é o fato de discriminar os pobres. Estão presentes no sistema educativo brasileiro "mecanismos de exclusão socioeconômica de grande parte da população brasileira e fatores de discriminação de várias naturezas, como aqueles relativos à condição racial, de gênero, moradia, idade" 
Revista Triângulo

ISSN 2175-1609

(HADDAD, 2007, p. 220).

Há dificuldades também quanto às condições físicas para o trabalho escolar, com deficiência no número de bibliotecas, laboratórios de Ciências e de Informática, acesso à Internet, instalações inadequadas, falta de material didático-pedagógico, entre outros (HADDAD, 2007, 2008). Outro fator que prejudica a qualidade da educação é a precariedade do trabalho docente, "resultando em falta de estímulo e insuficiência de professores" (HADDAD, 2007, p. 220).

Segundo Haddad (2008, 2013), é necessário ouvir os atores da educação: professores, pais, estudantes e comunidade escolar.

Talvez tenhamos que começar por aí, dando voz aos que fazem e sofrem a educação no seu dia a dia, reconhecendo suas dificuldades, seus acertos, suas frustrações e sonhos para construir um sistema educacional que efetivamente ajude a construir um Brasil mais justo e democrático e cujo desenvolvimento seja o resultado das expectativas e necessidades de toda a população (HADDAD, 2013, p.11).

O sistema educacional brasileiro, infelizmente, é caracterizado por "uma escola pobre para os pobres" (HADDAD, 2008, p. 33), que oferta piores condições para os menos favorecidos e reproduz na educação as desigualdades da sociedade (HADDAD, 2008). São persistentes e profundas as desigualdades no trabalho e nas condições de vida.

A educação, sozinha, não consegue eliminar a pobreza e as desigualdades históricas, mas "continua sendo fator fundamental e estratégico para a promoção de uma sociedade mais justa, democrática e sustentável para todas as mulheres e homens" (CARREIRA, 2013, p. 104). A importância da educação, portanto, é indiscutível para um pleno desenvolvimento da sociedade, devendo estar alinhada a outras estratégias para a redução de desigualdades e injustiças que historicamente acompanham a sociedade brasileira.

\section{MATERIAIS E MÉTODOS}

Este trabalho foi desenvolvido a partir de um Seminário oferecido pelo Programa de PósGraduação em Educação da Universidade de Caxias do Sul, organizado pelo Prof. Dr. Sérgio Haddad. Durante os encontros, foram discutidos: o conceito de desenvolvimento e sua relação com a educação; as origens das desigualdades sociais no Brasil e a nível global; e a inter-relação entre educação e desigualdade no Brasil.

Foram indicadas e debatidas leituras distribuídas em quatro eixos conceituais: a distribuição da riqueza; desigualdades no Brasil; as desigualdades na educação; e relação entre educação, desigualdade e desenvolvimento. Dentre as leituras, destacam-se: os livros $O$ capital no 


\section{Revista Triângulo}

ISSN 2175-1609

século XXI, de Thomas Piketty e Trajetórias das desigualdades: como o Brasil mudou nos últimos 50 anos, organizado por Marta Arretche; um relatório do Conselho de Desenvolvimento Econômico e Social sobre as desigualdades na escolarização no Brasil; artigos publicados pelo prof. Haddad a respeito do tema do Seminário; além de outros textos complementares.

Tendo como base os textos indicados e, preferencialmente, lidos antes dos encontros, o Seminário foi desenvolvido com a mediação do professor em diálogo com os participantes. As interações realizadas nos encontros presenciais promoveram importantes reflexões sobre as relações entre educação, desigualdade e desenvolvimento. Foram pensados e discutidos aspectos históricos, econômicos e sociais no contexto da educação brasileira, resultando em diferentes produções escritas - uma das quais é apresentada no presente trabalho.

\section{ANÁLISE DOS DADOS E RESULTADOS}

\subsection{Educação, desigualdade e desenvolvimento}

Segundo Haddad (2013), a educação deve ser pensada conciliando duas visões: como formadora de mão-de-obra, voltada ao crescimento econômico e ao direito por trabalho digno; e como direito humano, para a valorização do potencial sociocultural da população, o exercício da cidadania e melhores condições de vida e de participação política e social. Os processos educacionais, assim, precisam ser pensados considerando não apenas as necessidades do mercado de trabalho e consumo, mas também a participação cidadã e as consequências sociais, culturais e ambientais do desenvolvimento.

A educação não pode ser reduzida a uma ferramenta para que os jovens consigam um emprego, em um objetivo estritamente econômico. É preciso considerar a dimensão formativa da educação, que "facilita ao cidadão a participação política, a convivência em sociedade e a preservação e o uso sustentável dos bens naturais" (HADDAD, 2014, p. 34). A educação é um direito humano que somente se realiza plenamente se não estiver dissociado de outros direitos, como saúde, moradia e transportes. Desse modo, não deve ser pensada na "lógica reducionista da economia", que prioriza produção, consumo, crescimento econômico, emprego, competição e individualismo (HADDAD, 2014).

Mesmo com avanços no século XXI, o desenvolvimento no Brasil ainda gera grande desigualdade, destinando os ganhos do desenvolvimento à parte da população que possui mais bens e privilégios. A educação, nesse contexto, reafirma a desigualdade ao ofertar uma educação de menor qualidade aos que possuem menos condições financeiras, o que deve ser revisto para que a educação possa efetivar a promoção humana e de justiça social (HADDAD, 2008, 2013). Segundo Haddad, "só haverá democracia educacional se houver democracia social" (2008, p. 32). 


\section{Revista Triângulo}

ISSN 2175-1609

Apesar dos índices de escolaridade terem aumentado, as desigualdades de acesso ao saber foram agravadas ao transformar a escola em uma "caricatura de inclusão social" (LIBÂNEO, 2012, p. 23). Segundo Libâneo, há uma escola do conhecimento para os ricos e uma escola voltada apenas ao assistencialismo para os pobres, dualismo este que é "perverso por reproduzir e manter desigualdades sociais" (2012, p. 13).

Essa diferenciação entre uma escola para ricos e outra para pobres é explorada por Libâneo, que as distingue, respectivamente, como uma escola com foco na aprendizagem e nas tecnologias - para os ricos - e outra com missão assistencial - para os pobres. Esta escola para os pobres, assim, é concebida com a função de "incluir populações excluídas ou marginalizadas pela lógica neoliberal, sem que os governos lhe disponibilizem investimentos suficientes, bons professores e inovações pedagógicas" (LIBÂNEO, 2012, p. 23). Apesar desta diferenciação feita por Libâneo, não é esclarecido como a formação humana é considerada dentro das concepções de educação de cada uma destas escolas.

A educação pública tem seus ideais igualitários comprometidos pela falta de políticas que procurem combater as desigualdades sociais (HADDAD, 2007):

Há dois consensos que podem ser encontrados em qualquer parte deste país e entre qualquer grupo social: a grande importância da educação para a construção de uma sociedade justa, democrática e sustentável; e a insuficiência do sistema público de ensino em garantir, com quantidade e qualidade, este direito (HADDAD, 2008, p. 32).

Segundo Haddad (2013), ofertar um ensino de qualidade é um grande desafio que deve ser enfrentado no Brasil, juntamente com a efetiva universalização do atendimento. $\mathrm{O}$ aumento no número de matrículas na educação básica não foi acompanhado por uma melhoria na qualidade da educação, de modo que grande parte dos jovens não dominam minimamente leitura, escrita e matemática (CARREIRA, 2013; HADDAD, 2008, 2014). A preocupação em assegurar o acesso à educação tem sido mais eficiente do que as ações para promover a permanência na escola e uma efetiva aprendizagem (HADDAD, 2008).

Segundo dados do IBGE, 27\% da população brasileira entre 15 e 64 anos de idade é considera analfabeta funcional (INSTITUTO PAULO MONTENEGRO, 2016). São pessoas que, mesmo alfabetizadas, não conseguem interpretar textos simples e não têm habilidades de leitura, escrita e cálculo básico (CARREIRA, 2013). Estes dados são relevantes para observar o domínio destas habilidades, porém é válido questionar se apenas estes índices são suficientes, já que não avaliam diretamente questões relativas à formação humana.

As formas de construção e implementação das políticas de educação historicamente são insuficientes no enfrentamento das desigualdades na educação brasileira, quanto ao acesso, à permanência e à qualidade da aprendizagem: 
O modelo de ampliação do acesso à educação no Brasil, desde os anos de 1970, foi baseado no baixo gasto por aluno e na consequente baixa qualidade do atendimento, concretizada em turmas com número excessivo de estudantes, salários e condições indignas de trabalho dos profissionais de educação, entre outros problemas (CARREIRA, 2013, p. 49).

A falta de qualidade na educação, aliada a barreiras ao acesso - como falta de transporte, infraestrutura inadequada e dificuldade de acessibilidade para alunos com deficiência (UNICEF, 2012) -, prejudica os alunos e as famílias, especialmente nas classes sociais menos favorecidas. A escola, assim, "esconde mecanismos internos de exclusão ao longo do processo de escolarização, antecipadores da exclusão na vida social” (LIBÂNEO, 2012, p. 24).

O fator econômico com maior influência na educação é a pobreza. Conforme publicação do Fundo das Nações Unidas para a Infância (UNICEF) sobre a exclusão escolar no Brasil, "quanto mais baixa a renda familiar, menores são as taxas de frequência à escola" (2014, p. 35). As crianças e os adolescentes mais excluídos das condições de acesso e permanência na escola são oriundos de famílias em situação de vulnerabilidade econômica e social. Adolescentes vindos de famílias pobres apresentam maior risco de evasão, já que "muitos acabam por trocar os estudos pelo trabalho, seja para ajudar na sobrevivência da família seja para ter acesso a bens de consumo que seus pais não têm condições de lhes proporcionar" (UNICEF, 2014, p. 28).

As condições do sistema de ensino brasileiro refletem, portanto, as desigualdades existentes na sociedade, com a exclusão de pessoas pertencentes a grupos historicamente excluídos da sociedade brasileira: negros, índios, quilombolas, pobres, que vivem na zona rural, com deficiência ou vindos de um núcleo familiar com pouca ou nenhuma escolaridade (UNICEF, 2012, 2014). Quanto à escolaridade e considerando que a educação tem um impacto significativo em longo prazo, o investimento na geração atual tende a influenciar de maneira positiva a educação das próximas gerações (UNICEF, 2014).

Embora as desigualdades de renda tenham diminuído e o acesso ao Ensino Fundamental tenha aumentado, o país ainda não conseguiu garantir a universalização da escola obrigatória (CARREIRA, 2013; UNICEF, 2012). Conforme relatório sobre a Educação Básica no Brasil, as crianças e adolescentes pobres que ingressam na escola têm dificuldades para avançar nos estudos, o que faz com que as pessoas das classes sociais mais ricas tenham quase o dobro a mais de anos de estudo que as pessoas das classes mais pobres (UNICEF, 2012).

Assim, para que o direito de aprender seja garantido a todos, é necessário incluir os milhões de crianças e adolescentes que estão fora da escola (UNICEF, 2014) e dedicar maior atenção aos que apresentam risco de abandono devido, especialmente, à vulnerabilidade econômica e 


\section{Revista Triângulo}

ISSN 2175-1609

social. Aliado a isso, é imprescindível investir na formação humana de cada uma destas crianças e adolescentes, preparando-os para efetivamente serem capazes de refletir e pensar criticamente.

\section{CONSIDERAÇÕES FINAIS}

Profundas desigualdades sociais, econômicas, políticas e educacionais marcam o Brasil, apresentando desafios que precisam ser vencidos, especialmente quanto à garantia de acesso e permanência de todas as crianças e adolescentes na escola. Além disso, é preciso melhorar a infraestrutura das escolas, valorizar os professores e também refletir sobre as concepções de educação. Conforme Rueda et al., as políticas educacionais não devem ser pautadas em um "modelo fundamentado nos valores do mercado, baseado na lógica da competição e do rendimento. Devemos reivindicar um sistema educacional que entenda a educação como um direito e uma oportunidade de desenvolvimento integral do ser humano" (2014, p. 155).

Assim, é um desafio para o Brasil garantir que todas as crianças tenham acesso à educação e concluam cada etapa de escolarização na idade adequada, aprendendo conteúdos e valores de cidadania e respeito nesse processo (SAMPAIO, 2014). Para conquistar a igualdade social na escola, Libâneo defende que seja proporcionado, em iguais condições a todas as crianças e jovens, "o acesso aos conhecimentos da ciência, da cultura e da arte, bem como o desenvolvimento de suas capacidades intelectuais e a formação da cidadania” (2012, p. 26).

De acordo com os relatórios da UNICEF sobre a situação da educação brasileira, a exclusão escolar "é um fenômeno complexo e a sua superação requer mais do que boa vontade. É preciso que o Estado cumpra o seu dever constitucional e que haja a participação e o compromisso de toda a sociedade e de cada um de nós" (UNICEF, 2012, p. 5).

São necessárias, portanto, estratégias para proporcionar melhores condições de acesso e permanência na escola, desenvolvidas para todos os grupos sociais e associadas a outras ações que visem reduzir as desigualdades sociais no Brasil, com uma educação sem discriminação. A exclusão escolar deve ser enfrentada por toda a sociedade, investindo na formação cidadã de todas as crianças e jovens.

Importante destacar que este texto se propõe a observar mais genericamente a avaliação da educação no Brasil. O enfoque é colocado sobre as questões de desigualdade, não sendo necessariamente um debate aprofundado e filosófico, e sim apenas um olhar inicial sobre o assunto. Mais relevante do que analisar os dados quantitativos de índices relacionados à educação, é observar como a formação humana ocorre nas escolas. Observar a aprendizagem da leitura, escrita e matemática é importante, mas a formação para a cidadania exige mais do que isso. É preciso promover a formação de crianças e jovens críticos e conscientes, que tenham condições de refletir sobre sua própria condição e lutar pelas mudanças necessárias. 


\section{Revista Triângulo}

ISSN 2175-1609

\section{REFERÊNCIAS}

ARRETCHE, Marta. Conclusões: As políticas na trajetória da democracia à redução das desigualdades. In: ARRETCHE, Marta (Org.). Trajetórias das desigualdades: como o Brasil mudou nos últimos cinquenta anos. São Paulo: Editora Unesp, 2015. p. 423-455.

BARROS, Ricardo Paes de; HENRIQUES, Ricardo; MENDONÇA, Rosane. Desigualdade e pobreza no Brasil: retrato de uma estabilidade inaceitável. Revista Brasileira de Ciências Sociais, [São Paulo], v. 15, n. 42, p. 123-142, 2000.

BRASIL. Constituição da República Federativa do Brasil: texto constitucional promulgado em 5 de outubro de 1988, com as alterações determinadas... Brasília: Senado Federal, 2016.

BRASIL. Estatuto da criança e do adolescente: lei $\mathrm{n}^{\mathrm{o}}$ 8.069, de 13 de julho de 1990. 6 ed. Brasília: Senado Federal, 2005.

BRASIL. Lei de diretrizes e bases da educação nacional: lei no 9.394, de 20 de dezembro de 1996. 14 ed. Brasília: Câmara dos Deputados, 2017.

CARREIRA, Denise (Coord.). Informe Brasil: gênero e educação. São Paulo: Ação Educativa, 2013.

CONSELHO DE DESENVOLVIMENTO ECONÔMICO E SOCIAL. As desigualdades na escolarização no Brasil: Relatório de Observação no 5. Brasília: CDES, 2014.

HADDAD, Sérgio. Educação e desenvolvimento. Le Monde Diplomatique Brasil, [São Paulo], ano 8, n. 85, p. 34, 2014.

HADDAD, Sérgio. Educação e desenvolvimento: uma discussão necessária. Revista Política Social e Desenvolvimento, Campinas, ano 1, n. 2, p. 8-11, 2013.

HADDAD, Sérgio. Educação e exclusão. In: MARCOVITCH, Jacques (Org.). Crescimento econômico e distribuição de renda: prioridades para ação. São Paulo: EDUSP: Senac São Paulo, 2007. p. 201-226.

HADDAD, Sérgio. Educação e exclusão. Le Monde Diplomatique Brasil, [São Paulo], ano 1, n. 10, p. 32-33, 2008.

INSTITUTO BRASILEIRO DE GEOGRAFIA E ESTATÍSTICA. Pesquisa Nacional por Amostra de Domicílios: síntese de indicadores 2014. Rio de Janeiro: IBGE, 2015.

INSTITUTO PAULO MONTENEGRO. Indicador de analfabetismo funcional: estudo especial sobre analfabetismo e mundo do trabalho. São Paulo: Instituto Paulo Montenegro, 2016.

LIBÂNEO, José Carlos. O dualismo perverso da escola pública brasileira: escola do conhecimento para os ricos, escola do acolhimento social para os pobres. Educação e

\begin{tabular}{l|l|l|l|l|l} 
(C) Rev. Triang. & Uberaba, MG & v.11 & n.2 & p. 199-210 & Maio/Ago. 2018 \\
\hline
\end{tabular}


Revista Triângulo

ISSN 2175-1609

Pesquisa, São Paulo, v. 38, n. 1, p. 13-28, 2012.

PIKETTY, Thomas. O capital no século XXI. Rio de Janeiro: Intrínseca, 2014.

RUEDA, Daniela et al. Educação no Brasil: desafios e avanços, na perspectiva dos adolescentes e dos jovens. In: UNICEF. O enfrentamento da exclusão escolar no Brasil. Brasília: UNICEF, 2014. p. 152-155.

SAMPAIO, Carlos Eduardo Moreno. Acesso e permanência hoje e perspectivas para o futuro. In: UNICEF. O enfrentamento da exclusão escolar no Brasil. Brasília: UNICEF, 2014. p. 182-192.

SARAIVA, Karla; VEIGA-NETO, Alfredo. Modernidade líquida, capitalismo cognitivo e educação contemporânea. Educação e Realidade, Porto Alegre, v. 34, n. 2, p. 187-201, 2009.

SENNETT, Richard. A corrosão do caráter: consequências pessoais do trabalho no novo capitalismo. Rio de Janeiro: Record, 1999.

SILVA, Roberto Rafael Dias da. Sennett \& a Educação. Belo Horizonte: Autêntica, 2015.

UNICEF. Brasil: acesso, permanência, aprendizagem e conclusão da Educação Básica na idade certa: direito de todas e de cada uma das crianças e dos adolescentes. Brasília: UNICEF, 2012. Iniciativa global pelas crianças fora da escola. Resumo executivo.

UNICEF. O enfrentamento da exclusão escolar no Brasil. Brasília: UNICEF, 2014. 